OPEN ACCESS

Edited by:

Zongxin Ling,

Zhejiang University, China

Reviewed by:

Chen Chen,

Capital Medical University, China

Xu Yang

California State Polytechnic University,

Pomona, United States

Zhengqiang $\mathrm{Hu}$,

Sichuan University, China

*Correspondence: Bingbing Xiao

doctorxbb@163.com

Huixia Yang

yanghuixia@bjmu.edu.cn

Specialty section: This article was submitted to Infectious Diseases - Surveillance, Prevention and Treatment a section of the journal

Frontiers in Medicine

Received: 16 January 2020 Accepted: 21 May 2020

Published: 19 June 2020

Citation:

He Y, Niu X, Wang B, Na R, Xiao B and Yang $H$ (2020) Evaluation of the

Inhibitory Effects of Lactobacillus gasseri and Lactobacillus crispatus on

the Adhesion of Seven Common Lower Genital Tract Infection-Causing Pathogens to Vaginal Epithelial Cells.

Front. Med. 7:284

doi: 10.3389/fmed.2020.00284

\section{Evaluation of the Inhibitory Effects of Lactobacillus gasseri and Lactobacillus crispatus on the Adhesion of Seven Common Lower Genital Tract Infection-Causing Pathogens to Vaginal Epithelial Cells}

\author{
Yuanhui He, Xiaoxi Niu, Ben Wang, Risu Na, Bingbing Xiao* and Huixia Yang* \\ Department of Obstetrics and Gynecology, Peking University First Hospital, Beijing, China
}

Background/Purpose: Lactobacillus colonization is important to maintain urogenital flora stability and prevent pathogenic infection. Different Lactobacillus species have distinct properties and effects on the urogenital flora. To select probiotics that colonize the vagina and provide protection against pathogenic infection, we evaluated the adhesion of five Lactobacillus strains and their inhibitory effects on the adhesion of pathogens to vaginal epithelial cells (VECs).

Methods and Materials: (1) Lactobacillus adhesion experiments: VK2/E6E7 and primary VECs were used to evaluate the adhesion of two Lactobacillus gasseri and three Lactobacillus crispatus strains. The adhesion of these five Lactobacillus strains was compared. (2) Adhesion inhibition experiments: The inhibitory effects of the five Lactobacillus strains on the adhesion of pathogens (Gardnerella, Mobiluncus, Candida albicans, Streptococcus agalactiae, Staphylococcus aureus, Escherichia coli, and Enterococcus faecalis) were evaluated by adhesion exclusion, displacement, and competition experiments.

Results: (1) Lactobacillus adhesion was stronger in the primary VECs than in the VK2/E6E7 VECs $(P<0.05)$. The adhesion of the three $L$. crispatus strains was stronger than that of the two $L$. gasseri strains $(P<0.05)$. L. crispatus $4 \#$ showed the strongest adhesion. (2) The exclusion, displacement, and competition experiments showed that all five Lactobacillus strains significantly inhibited the adhesion of the seven pathogenic strains to the VECs $(P<0.05)$. The displacement effect was stronger than the exclusion and competition effects of each Lactobacillus strain. (3) The results of the exclusion, displacement, and competition experiments indicated that $L$. gasseri $1 \#$ showed the strongest adhesion inhibition of $C$. albicans and S. agalactiae. L. crispatus $3 \#$ showed the strongest adhesion inhibition of $S$. aureus, whereas $L$. crispatus $4 \#$ showed the strongest adhesion inhibition of Gardnerella, Mobiluncus, E. coli, and E. faecalis. 


\begin{abstract}
Conclusion: The source of the VECs might not affect the selection of the most adhesive Lactobacillus strain. L. crispatus showed stronger VEC adhesion than L. gasseri. The degree of antagonism of the Lactobacillus strains toward the different pathogens varied. This result provides incentives for personalized clinical treatment.
\end{abstract}

Keywords: Lactobacillus gasseri, Lactobacillus crispatus, adhesion inhibition, lower genital tract infection-causing pathogens, vaginal epithelial cells

\section{INTRODUCTION}

Bacterial vaginosis (BV), vulvovaginal candidiasis (VVC), and aerobic vaginitis (AV) are common lower genital tract diseases that seriously affect female reproductive health (14). They are associated with infertility, ectopic pregnancy, and sexually transmitted diseases. Gardnerella and Mobiluncus are the most common causative pathogens of BV (5), whereas Candida albicans is the most common causative pathogen of VVC (6). AV is often associated with pathogens such as Streptococcus agalactiae, Staphylococcus aureus, Escherichia coli, and Enterococcus faecalis (7).

Antibiotics play an important role in the treatment and prevention of female reproductive tract infections, but their longterm use increases the rates of bacterial resistance and disease recurrence (8) and can severely disrupt the vaginal microbiota (9). Disease recurrence compromises the patient's quality of life and mental state (10). The active investigation of new methods for protection against pathogens is an important measure to prevent genital tract infections.

Various clinical studies have indicated that microecological preparations, administered orally or vaginally, can significantly reduce the incidence and recurrence rates (11-13), prolong the recurrence period, improve the recovery rate (14), relieve the symptoms (15), and improve the vaginal microecological patterns (16) of BV and VVC. There is a significant correlation between Lactobacillus colonization in the vagina and clinical outcomes $(12,13,17)$. Lactobacillus, as the dominant bacterium, can balance the microbial flora of the genitourinary tract through a variety of mechanisms including host immune regulation, recovery of the vaginal flora, and interference with pathogen colonization $(18,19)$. It is important for restoring the normal state of the flora and preventing infections and disease recurrence $(9,18,20,21)$. Adhesion plays a key role in the beneficial effects of Lactobacillus (9) and is also the key virulence factor for pathogens such as Gardnerella, C. albicans, and E. coli (9).

It is of great importance to select better probiotic strains for clinical application. At present, more than 20 types of lactic acidproducing bacteria can be detected in the vagina by sequencing, and Lactobacillus gasseri and Lactobacillus crispatus are the main lactobacilli in healthy women (22-24). Their use can reduce the risk of the vigorous growth of non-native Lactobacilli in the urogenital tract (25). They produce antibacterial substances such as lactic acid and hydrogen peroxide $(26,27)$, adhere to vaginal epithelial cells (VECs) to form a protective film while inhibiting pathogen adhesion (26), and thus protect the vaginal epithelial barrier from pathogen colonization and invasion (28-30).
To select probiotics that could successfully colonize the vagina and protect it against pathogenic infection, we selected five Lactobacillus (two L. gasseri and three L. crispatus) strains, isolated from vaginal samples obtained from Chinese women, to evaluate their adhesion to the VECs and their ability to inhibit the adhesion of seven pathogens associated with common reproductive tract infections.

\section{MATERIALS AND METHODS}

\section{Origin and Culture of Bacterial Strains}

Twelve archived and previously characterized clinical isolates of Lactobacillus and pathogenic strains (Table 1) were tested to determine their adhesion properties and the inhibitory effects of Lactobacillus on pathogen adhesion. The Lactobacilli were isolated from vaginal samples obtained from healthy volunteers ( $>18$ years of age) at the health checkup clinic of our hospital. These women of childbearing age did not suffer from any urogenital tract infections. They had not used antibacterial drugs within 3 months of admission, and they had not had sexual intercourse 1 week before admission. The pathogens were isolated from patients ( $>18$ years of age) with urogenital tract infections. All isolates were identified by standard methods used in clinical microbiology laboratories. Every strain to be tested was recovered and purified before the experiment to ensure bacterial viability and purity. The strains were incubated at $37^{\circ} \mathrm{C}$ in an atmosphere of $5 \% \mathrm{CO}_{2}$ for $48 \mathrm{~h}$. Each bacterial suspension was adjusted to a concentration of $1.0 \times 10^{8} \mathrm{CFU} / \mathrm{mL}$.

\section{Origin and Culture of VECs}

Two kinds of VECs, including the VK2/E6E7-ATCC-CRL2616 (VK2/E6E7) and primary VECs, were used in our study (Table 1). The VK2/E6E7 VECs were obtained from the American Type Culture Collection (ATCC; Rockville, MD, USA). This cell line from the normal vaginal mucosal tissue of a premenopausal woman, who underwent anterior-posterior vaginal repair surgery, was established in 1996 (31). Primary VECs were collected from a healthy volunteer during the 17 th and 18th days of her menstrual cycle. The volunteer had not used antibiotics, spermicidal products, or oral contraceptives, and had no known vaginal pathology. The VECs were digested with $0.15 \%$ trypsin and $0.01 \%$ EDTA for $5 \mathrm{~min}$, and the digestion was terminated using Dulbecco's Modified Eagle's Medium-nutrient mixture F-12 (DMEM-F12) medium that contained 10\% fetal bovine serum. Next, the cells were centrifuged for $10 \mathrm{~min}(13,400$ $\times \mathrm{g}$ ), and the supernatant was discarded. The VEC concentration was adjusted to $10^{5}$ cells $/ \mathrm{mL}$ using keratinocyte serum-free 
TABLE 1 | The species, number, full name, and abbreviated name of the bacteria and vaginal epithelial cells used in this study.

\begin{tabular}{|c|c|c|c|}
\hline Species & Number & Full name & Brief name \\
\hline \multirow[t]{2}{*}{ Lactobacillus gasseri } & 2 & Lactobacillus gasseri 1\# & L. gasseri 1\# \\
\hline & & Lactobacillus gasseri 2\# & L. gasseri 2\# \\
\hline \multirow[t]{3}{*}{ Lactobacillus crispatus } & 3 & Lactobacillus crispatus 3\# & L. crispatus 3\# \\
\hline & & Lactobacillus crispatus 4\# & L. crispatus 4\# \\
\hline & & Lactobacillus crispatus 5\# & L. crispatus 5\# \\
\hline Gardnerella & 1 & Gardnerella & Gardnerella \\
\hline Mobiluncus & 1 & Mobiluncus & Mobiluncus \\
\hline Candida albicans & 1 & Candida albicans & C. albicans \\
\hline Streptococcus agalactiae & 1 & Streptococcus agalactiae & S. agalactiae \\
\hline Staphylococcus aureus & 1 & Staphylococcus aureus & S. aureus \\
\hline Escherichia coli & 1 & Escherichia coli & E. coli \\
\hline Enterococcus faecalis & 1 & Enterococcus faecalis & E. faecalis \\
\hline \multirow[t]{2}{*}{ Vaginal epithelial cells } & 2 & Vaginal epithelial cells VK2/E6E7-ATCC-CRL-2616 & VK2/E6E7 VECS \\
\hline & & Primary vaginal epithelial cells & Primary VECs \\
\hline
\end{tabular}

medium (K-SFM) containing antibiotics (counted by the cellcounting plate method and then diluted to the appropriate concentration). VEC suspensions $(2 \mathrm{~mL})$ were pipetted into a 6-well-culture plate with a built-in coverslip and kept for $18 \mathrm{~h}$ until adhesion to the cells. The VECs that did not adhere were removed by washing thrice with DMEM-F12 medium (without antibiotics) containing $10 \%$ fetal calf serum. Both kinds of adherent VECs in the RPMI1640 medium in each well were used to evaluate the adhesion of the five Lactobacillus strains. Only the adherent VK2/E6E7 VECs in each well were used for the adhesion inhibition experiments.

\section{Adhesion of Lactobacillus to the VECs}

VK2/E6E7 and primary VECs were used in this experiment. A Lactobacillus suspension $(2 \mathrm{~mL})$, at a concentration of $1.0 \times 10^{8}$ $\mathrm{CFU} / \mathrm{mL}$, was added to the adherent VECs in each well. They were then cultivated at $37^{\circ} \mathrm{C}$ in an atmosphere of $5 \% \mathrm{CO}_{2}$ for $1 \mathrm{~h}$. The coverslip was removed, fixed in methanol for $15 \mathrm{~min}$, and subjected to Gram staining. Lactobacillus strains were identified based on their color and morphology and counted. Lactobacillus adhesion was assessed using the adhesion index, which was calculated as follows: Adhesion index = adhering bacteria/cell number. The adherent Lactobacillus number is the total quantity of Lactobacilli adherent to 50 intact VECs, which were selected randomly. We observed these intact VECs and counted the Lactobacillus number using a light microscope at $1000 \times$ magnification under oil immersion (32).

\section{Lactobacillus-Mediated Inhibition of Pathogen Adhesion to VK2/E6E7 VECs}

The results of the Lactobacillus adhesion evaluation experiments indicated that the source of the VECs might not affect the selection of the most adhesive Lactobacillus strain. The VK2/E6E7 VECs, as a model cell line, ensured the reproducibility of the results of the current experiment. Therefore, it was chosen for evaluating the inhibitory effects of the five Lactobacillus strains on pathogen adhesion.
For the adhesion inhibition experiments, the concentration of each bacterium was adjusted to $1.0 \times 10^{8} \mathrm{CFU} / \mathrm{mL}$ with RPMI1640 broth using a microplate reader. The adhesion inhibition experiments included exclusion, displacement, and competition inhibition experiments. Briefly, the built-in coverslip was removed, and pathogen adhesion was evaluated upon completion of the experiment. Pathogen adhesion to the VK2/E6E7 VECs was assessed using the adhesion index, as described previously (32). The adherent pathogen number is the quantity of pathogens adherent to 50 intact VECs (VK2/E6E7) selected at random. The pathogens that adhered to the VK2/E6E7 VECs because adhesion inhibition by Lactobacillus was absent were defined as the control group. The pathogens that adhered to the VK2/E6E7 VECs after Lactobacillus antagonization were defined as the experimental group. The inhibitory effects of Lactobacillus on pathogen adhesion were negatively correlated with pathogen adhesion to the VK2/E6E7 VECs in the experimental group. In other words, the stronger the pathogen adhesion, the weaker the inhibitory effects of Lactobacillus on pathogen adhesion in the experimental group. The statistically significant difference in the pathogen adhesion indexes of the control and experimental groups indicated that Lactobacillus showed inhibitory effects on pathogen adhesion.

\section{Exclusion Experiment}

For the control group, the pathogen suspension $(1 \mathrm{~mL})$ was added to a well with adherent VK2/E6E7 VECs. For the experimental group, the Lactobacillus suspension $(1 \mathrm{~mL})$ was added to another well with adherent VK2/E6E7 VECs. They were incubated at $37^{\circ} \mathrm{C}$ in an atmosphere of $5 \% \mathrm{CO}_{2}$ for $1 \mathrm{~h}$. The non-adherent Lactobacillus and pathogens were removed by washing thrice with sterile phosphate-buffered saline (PBS). The pathogen suspension $(1 \mathrm{~mL})$ was added to the wells of the experimental and control groups and then incubated at $37^{\circ} \mathrm{C}$ in an atmosphere of $5 \% \mathrm{CO}_{2}$ for an additional hour. Adhesion was then evaluated. 


\section{Displacement Experiment}

The pathogen suspension $(1 \mathrm{~mL})$ was added to the wells containing adhered VK2/E6E7 VECs of the experimental and control groups. The cells were then incubated at $37^{\circ} \mathrm{C}$ in an atmosphere of $5 \% \mathrm{CO}_{2}$ for $1 \mathrm{~h}$. The non-adherent pathogens were removed by washing thrice with sterile PBS. Lactobacillus $(1 \mathrm{~mL})$ was added to the well of the experimental group, whereas the pathogens $(1 \mathrm{~mL})$ were added to that of the control group. The cells were then cultured at $37^{\circ} \mathrm{C}$ in an atmosphere of $5 \% \mathrm{CO}_{2}$ for another hour, and adhesion was evaluated.

\section{Competition Test}

For the experimental group, the Lactobacillus suspension (1 mL) and the pathogens were mixed and incubated in a well containing adhered VK2/E6E7 VECs. For the control group, the pathogen suspension $(1 \mathrm{~mL})$ and RPMI1640 broth $(1 \mathrm{~mL})$ were added to the well with the adherent VK2/E6E7 VECs. They were then incubated at $37^{\circ} \mathrm{C}$ in an atmosphere of $5 \% \mathrm{CO}_{2}$ for $1 \mathrm{~h}$, and adhesion was evaluated.

\section{Statistical Analysis}

All experimental steps were repeated in triplicate to ensure the reproducibility of the results. The adhesion index values are expressed as the mean \pm standard deviation (SD). An independent sample $t$-test was used to statistically analyze the differences between the two groups. A $P<0.05$ was considered statistically significant. The statistical software used was SPSS 20.0.

\section{Ethical Approval}

The Ethics Committee of Peking University First Hospital approved this study (V2.0/201504.20), and written informed consent was obtained from all participants.

\section{RESULTS AND DISCUSSION}

In the current study, five Lactobacillus strains, two L. gasseri and three L. crispatus strains, were isolated from the vagina of healthy women. The adhesion and inhibitory effects of these strains on pathogen adhesion were evaluated.

\section{Adhesion of Lactobacillus to VECs}

The adhesion of every Lactobacillus strain was stronger in the primary VECs than in the VK2/E6E7 VECs $(P<0.05)$ (Figure 1). These results indicated that the source of the VECs could affect the adhesion of the same Lactobacillus. The results could explain the differences in the effectiveness of Lactobacillus preparations in different populations (9, 25, 33 ) and the necessity of clinical trials to verify the antipathogenic effects of Lactobacillus preparations. The descending order of the five Lactobacillus strains based on the strongest adhesion to both types of VECs was 4\#, 3\#, 5\#, 2\#, and 1\# (Figure 1). The results indicated that the source of the VECs might not affect the selection of the most adhesive Lactobacillus strain. VK2/E6E7 VECs, as a model cell line, ensured the reproducibility of the current results. Therefore, it was used in

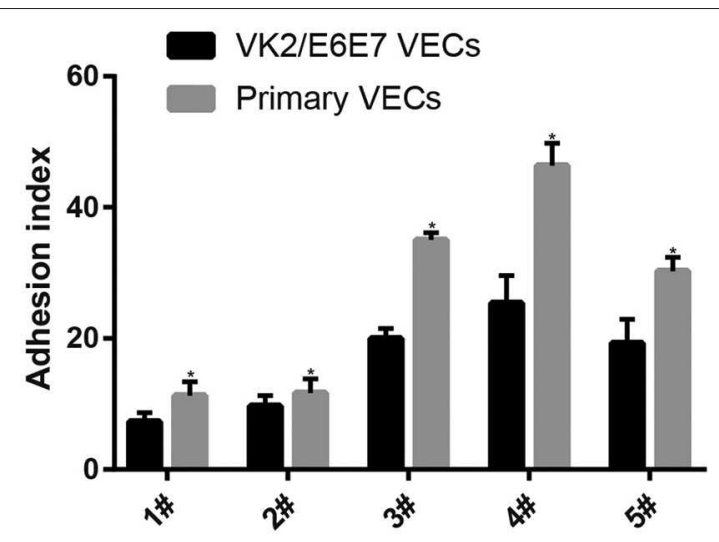

FIGURE 1 | Adhesion of the five Lactobacillus strains to VECs. Two kinds of VECs, VK2/E6E7, and primary VECs were used in this experiment. The adhesion of the five Lactobacillus strains to the VK2/E6E7 VECs, compared with that to primary VECs, was observed. Lactobacillus strains were identified by their color and morphology after Gram staining. Lactobacillus adhesion was assessed using the adhesion index: Adhesion index, adhering

Lactobacillus/cell number. The adhering Lactobacillus number is the total quantity of Lactobacilli adherent to 50 intact VECs, which were selected at random. These intact VECs were observed, and the Lactobacillus number was counted using a light microscope at $1000 \times$ magnification under oil immersion. Each adhesion index value is shown as the mean \pm SD. Student's $t$-test was performed. ${ }^{*} P<0.05$; the difference in the adhesion of each Lactobacillus strain to the VK2/E6E7 and primary VECs was statistically significant.

the experiments on the inhibitory effects of Lactobacillus on pathogen adhesion.

The adhesion of the three L. crispatus strains was stronger than that of the two L. gasseri strains $(P<0.05)$ (Figure 1 ), and this result was consistent with that of the study by Mousavi et al. (24). Although Mousavi et al. (24) chose Vero and HeLa cells to investigate Lactobacillus adherence, their results suggested that L. crispatus adhesion was stronger than L. gasseri adhesion, irrespective of the type of cells used. The L. crispatus and L. gasseri adhesion observed in both our and Mousavi's studies (24) was weaker than the Lactobacillus fermentum and Lactobacillus rhamnosus adhesion, which was investigated in the study by Ortiz et al. (34). Among the five Lactobacillus strains, L. crispatus $4 \#$ showed the strongest adhesion, and its adhesion indexes for primary and VK2/E6E7 VECs were 46.4 \pm 3.41 and $25.4 \pm 4.2$, respectively (Figure 2). The differences in the adhesion of the Lactobacillus strains could be attributed to the different sizes, species, and growth rates of Lactobacilli and the different adherent cell types $(24,34,35)$. Additionally, Lactobacillus adhesion was positively related to the secretion of a protein that contained MucBP-like domains (N506_1778) and a putative novel adhesin (N506_1709) with rib/alpha-like domain repeats and negatively related to the production of exopolysaccharides (36).

Adhesion not only helps Lactobacillus protect the mucosal epithelium but is also an important virulence factor of pathogens, beneficial for colonization, and biofilm formation (37). It is difficult for single-use antibiotics to penetrate biofilms (38); thus, biofilms protect pathogens and promote disease recurrence (39-41). 


\section{Effects of Lactobacillus on Pathogen Adhesion}

When the Lactobacillus-mediated antagonization of Gardnerella adhesion to the VK2/E6E7 VECs was tested, the descending orders of the strains with the strongest inhibition were $4 \#, 1 \#, 3 \#$, $5 \#$, and $2 \#$ in the exclusion experiments; $4 \#, 1 \#, 5 \#, 2 \#$, and $3 \#$ in the displacement experiments; and 4\#, 1\#, 5\#,3\#, and $2 \#$ in the competition experiments (Figure 3A). These results suggested that, among the five Lactobacillus strains, L. crispatus 4\# showed the strongest inhibition of Gardnerella adhesion. Similarly, $L$. crispatus $4 \#$ also showed the strongest inhibition of Mobiluncus (Figure 3B), E. coli (Figure 3F), and E. faecalis (Figure 3G) adhesion. L. crispatus $3 \#$ showed the strongest inhibition of $S$. aureus adhesion (Figure $3 \mathrm{E}$ ). The descending orders of the

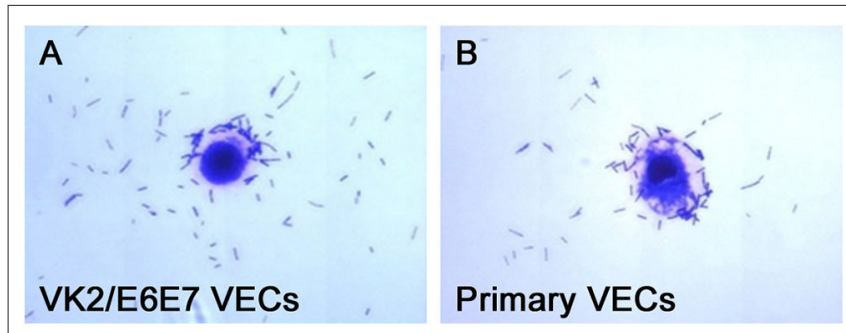

FIGURE 2 | Micrographs of L. crispatus 4\# adhesion to the VECs. L. crispatus 4 \# adhesion to (A) the VK2/E6E7 VECs and (B) the primary VECs is shown. strains with the strongest inhibitory effects on $S$. aureus were $3 \#, 1 \#, 2 \#, 5 \#$, and $4 \#$ in the exclusion experiments; $1 \#, 3 \#, 4 \#$, $2 \#$, and $5 \#$ in the displacement experiments; and 3\#, 5\#, 4\#, 1\#, and $2 \#$ in the competition experiments (Figure 3E). L. gasseri $1 \#$ showed the strongest inhibition of C. albicans (Figure 3C) and S. agalactiae (Figure 3D) adhesion. The descending orders of the strains with the strongest inhibitory effects on $S$. agalactiae adhesion were $1 \#, 5 \#, 4 \#, 3 \#$, and $2 \#$ in the exclusion experiments; $1 \#, 4 \#, 3 \#, 5 \#$, and $2 \#$ in the displacement experiments; and 1\#, $3 \#, 5 \#, 4 \#$, and $2 \#$ in the competition experiments (Figure 3D). However, further investigation of the antibacterial properties of Lactobacillus and clinical trials are required to confirm these results. More details are shown in Figures 3, 4.

All five Lactobacillus strains could effectively antagonize pathogen adhesion to the VK2/E6E7 VECs through exclusion, displacement, and competition inhibition $(P<0.05$, Figure 3$)$. However, the degree of the inhibitory effects of these strains on pathogen adhesion was not consistent. The current observations partially elucidated the mechanisms by which Lactobacillus preparations successfully antagonized pathogenic infections in clinical trials and showed that these effects were different $(9,25,33)$.

Lactobacillus effectively prevented pathogen adhesion to the VECs $(P<0.05$, Figure 3$)$, indicating that Lactobacillus adhesion to VECs was beneficial for the prevention of pathogenic infections. For each Lactobacillus strain, the displacement effect was stronger than the exclusion and competition effects on pathogen adhesion (Figure 3). This showed that Lactobacillus
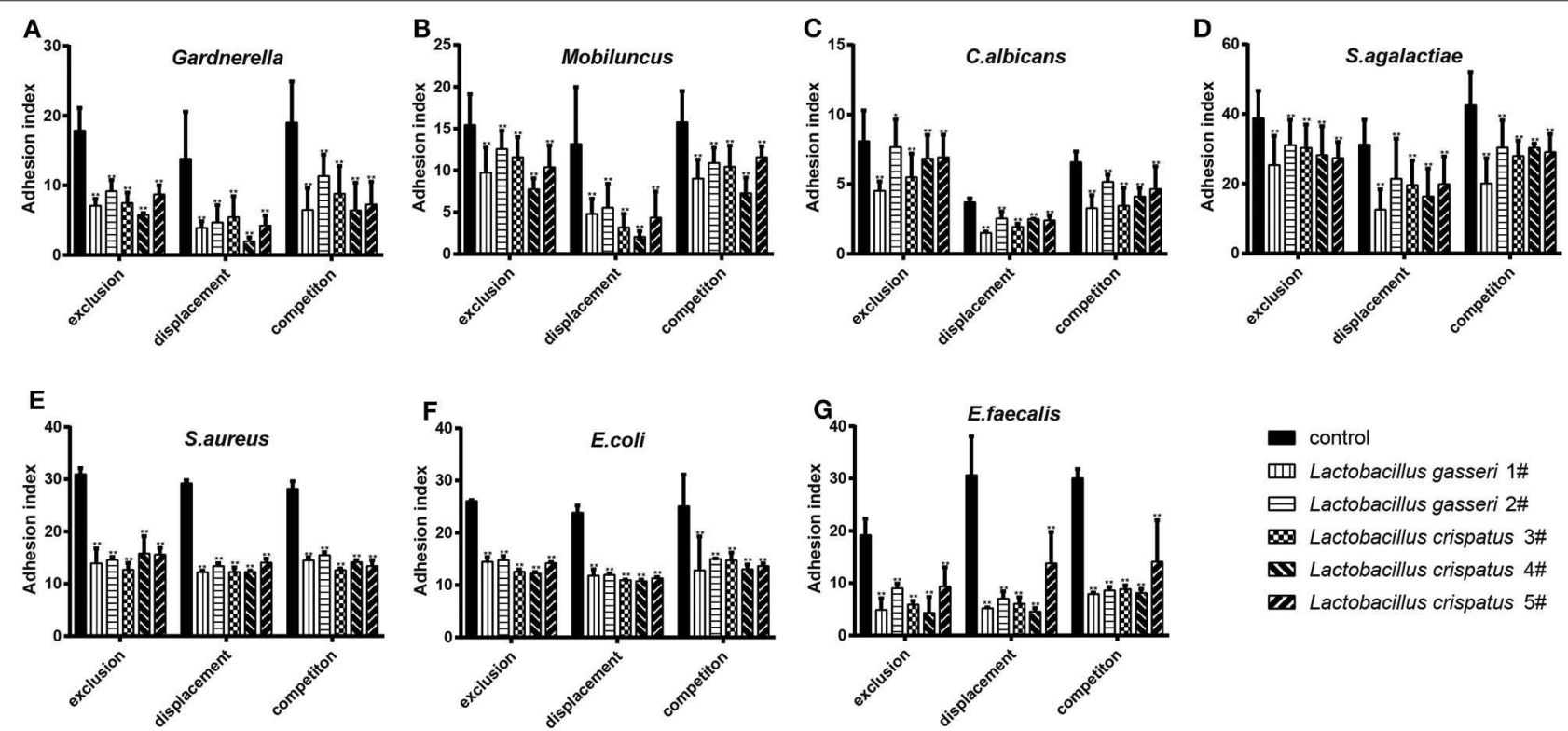

FIGURE 3 | Inhibitory effects of the five Lactobacillus strains on the adhesion of seven pathogenic strains to the VK2/E6E7 VECs. (A-G) The adhesion indexes of each pathogen in the control and experimental groups are shown. The control group shows the adhesion indexes of the pathogens when their adhesion was not inhibited by Lactobacillus (1\#, 2\#, 3\#, 4\#, and 5\#), whereas the experimental groups show the adhesion indexes of each pathogen after the exclusion, displacement, and competition effects of Lactobacillus antagonization. Adhesion index, adhering pathogen/cell number. The adhering pathogen number is the total quantity of pathogens adherent to 50 intact VECs, which were selected at random. These intact VECs were observed, and the pathogen number was counted using a light microscope at $1000 \times$ magnification under oil immersion. Each adhesion index value is shown as the mean \pm SD. Student's $t$-test was performed. ${ }^{\star} P<0.05$; ${ }^{\star \star} P$ $<0.001$; the difference in the adhesion indexes of the pathogens in the control and experimental groups was statistically significant. 


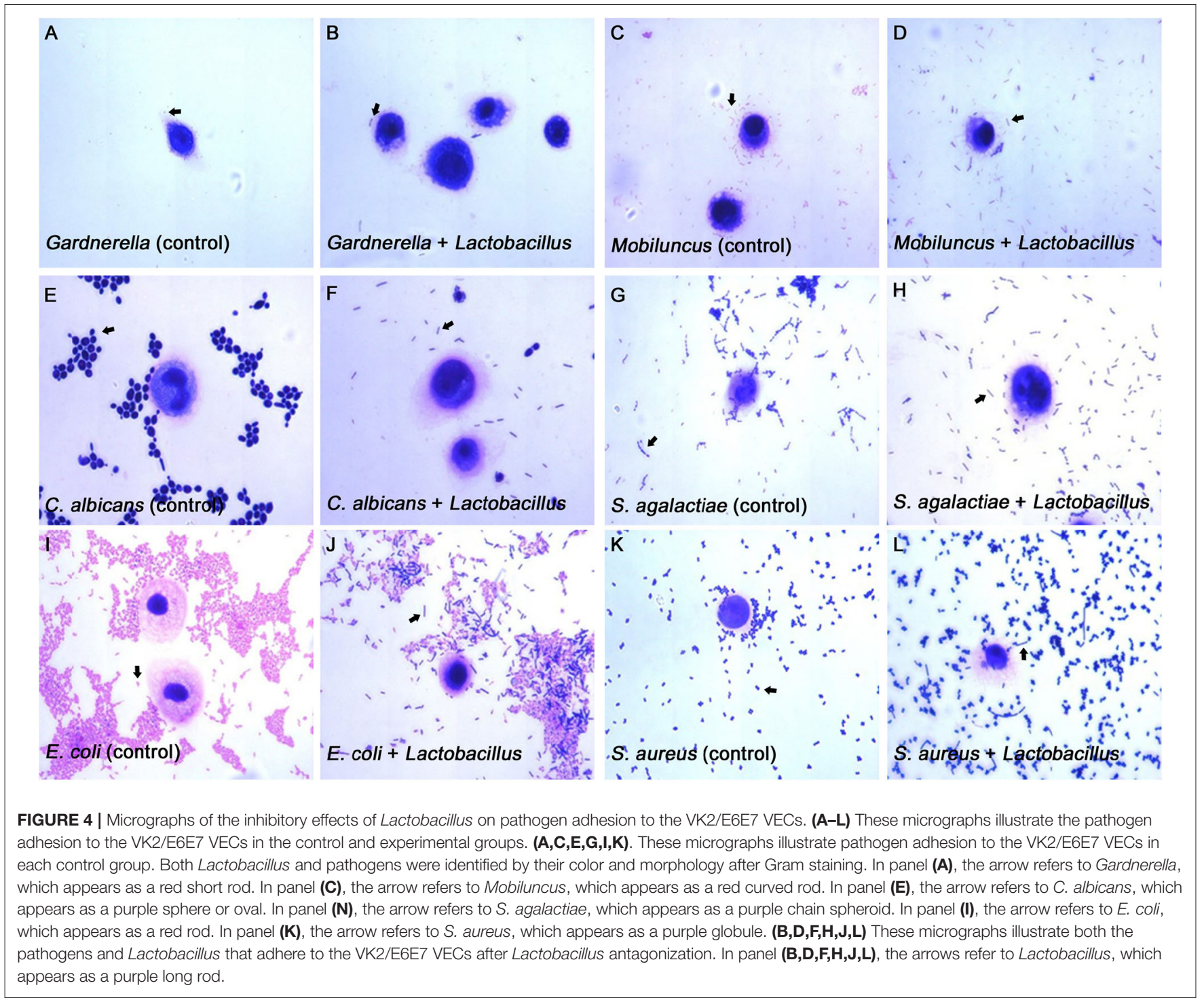

could effectively remove pathogens attached to the vaginal epithelium; thus, the results provide a basis for the preparation of Lactobacillus formulations for effective vaginal infection treatment. Multiple studies have shown that exopolysaccharides produced by Lactobacillus can shield adhesin and reduce pathogen adhesion to cell surfaces (42-44). Ortiz et al. (34) selected $L$. fermentum and $L$. rhamnosus to antagonize $S$. aureus and $S$. agalactiae adhesion to VECs; they found that the competition effect was far stronger than the exclusion and displacement effects. Abedi et al. (45) showed that the exclusion, displacement, and competition effects were not significantly different. These findings suggested that Lactobacillus could effectively prevent pathogen adhesion to VECs, but the effects of this adhesion inhibition varied; possible reasons for this include differences in the anti-adhesive substances produced when different Lactobacillus species compete for the same adhesion receptor (46). Anti-adhesive substances can degrade pathogenic carbohydrate receptors, construct biofilms, induce biosurfactant production, produce receptor analogs, and cause steric blockade or receptor inhibition $(45,47,48)$. Other possible causes include the time and initial amount of the pathogens in the in vitro culture (49), the bacterial size, and the presence of the $\operatorname{arcA}$ gene in the bacteria (48).

\section{CONCLUSION}

We found that the origin of the VECs might not affect the selection of the most adhesive Lactobacillus strains. L. crispatus showed stronger adhesion to the VECs than L. gasseri. The results of the exclusion, displacement, and competition inhibition experiments indicated that L. gasseri 1 \# could be used as a suitable probiotic for the prevention of $C$. albicans and $S$. agalactiae infections, whereas $L$. crispatus $3 \#$ could be used as a suitable probiotic against $S$. aureus infections. L. crispatus 4\# was found to be promising for the prevention of Gardnerella, Mobiluncus, E. coli, and E. faecalis infections. However, further research on 
the antibacterial properties of Lactobacillus, followed by clinical validation, is required.

\section{DATA AVAILABILITY STATEMENT}

All datasets generated for this study are included in the article/supplementary material.

\section{ETHICS STATEMENT}

The studies involving human participants were reviewed and approved by Ethics committee of Peking University first hospital. The patients/participants provided their written informed consent to participate in this study.

\section{AUTHOR CONTRIBUTIONS}

$\mathrm{YH}, \mathrm{XN}, \mathrm{BW}, \mathrm{RN}, \mathrm{BX}$, and HY conceived the study design. XN, $\mathrm{BW}$, and $\mathrm{RN}$ were responsible for the recruitment of volunteers

\section{REFERENCES}

1. Kindinger LM, Bennett PR, Lee YS, Marchesi JR, Smith A, Cacciatore $\mathrm{S}$, et al. The interaction between vaginal microbiota, cervical length, and vaginal progesterone treatment for preterm birth risk. Microbiome. (2017) 5:6. doi: 10.1186/s40168-016-0223-9

2. Jain JP, Bristow CC, Pines HA, Harvey-Vera A, Rangel G, Staines H, et al. Factors in the HIV risk environment associated with bacterial vaginosis among HIV-negative female sex workers who inject drugs in the Mexico-United States border region. BMC Public Health. (2018) 18:1032. doi: 10.1186/s12889-018-5965-9

3. Haddad LB, Wall KM, Kilembe W, Vwalika B, Khu NH, Brill I, et al. Bacterial vaginosis modifies the association between hormonal contraception and HIV acquisition. AIDS. (2018) 32:595-604. doi: 10.1097/QAD.0000000000001741

4. Kaambo E, Africa CWJ. The threat of aerobic vaginitis to pregnancy and neonatal morbidity. Afr J Reprod Health. (2017) 21:108-18. doi: 10.29063/ajrh2017/v21i2.12

5. Culhane JF, Nyirjesy P, McCollum K, Goldenberg RL, Gelber SE, Cauci S. Variation in vaginal immune parameters and microbial hydrolytic enzymes in bacterial vaginosis positive pregnant women with and without Mobiluncus species. Am J Obstet Gynecol. (2006) 195:516-21. doi: 10.1016/j.ajog.2006.02.036

6. Li T, Liu Z, Zhang X, Chen X, Wang S. Local probiotic Lactobacillus crispatus and Lactobacillus delbrueckii exhibit strong antifungal effects against vulvovaginal candidiasis in a rat model. Front Microbiol. (2019) 10:1033. doi: $10.3389 /$ fmicb. 2019.01033

7. Rumyantseva TA, Bellen G, Savochkina YA, Guschin AE, Donders GG. Diagnosis of aerobic vaginitis by quantitative real-time PCR. Arch Gynecol Obstet. (2016) 294:109-14. doi: 10.1007/s00404-015-4007-4

8. de Llano DG, Arroyo A, Cardenas N, Rodriguez JM, Moreno-Arribas MV, Bartolome B. Strain-specific inhibition of the adherence of uropathogenic bacteria to bladder cells by probiotic Lactobacillus spp. Pathog Dis. (2017) 75:ftx043. doi: 10.1093/femspd/ftx043

9. Cianci A, Cicinelli E, De Leo V, Fruzzetti F, Massaro MG, Bulfoni A, et al. Observational prospective study on Lactobacillus plantarum P 17630 in the prevention of vaginal infections, during and after systemic antibiotic therapy or in women with recurrent vaginal or genitourinary infections. J Obstet Gynaecol. (2018) 38:693-6. doi: 10.1080/01443615.2017.1399992

10. Fukazawa EI, Witkin SS, Robial R, Vinagre JG, Baracat EC, Linhares IM. Influence of recurrent vulvovaginal candidiasis on quality of life issues. Arch Gynecol Obstet. (2019) 300:647-650. doi: 10.1007/s00404-019-05228-3 and the collection of samples. $\mathrm{YH}, \mathrm{XN}$, and $\mathrm{RN}$ performed the laboratory assays. YH and BW performed the data analysis, and $\mathrm{YH}$ wrote the initial manuscript. BX and $\mathrm{HY}$ revised the manuscript. All the authors read and approved the final version of the manuscript.

\section{FUNDING}

This work was supported by the National Natural Science Foundation of China (no. 81200411 and no. 81971342).

\section{ACKNOWLEDGMENTS}

We would like to thank all the participants for their support and cooperation. We would also like to thank all the researchers, clinicians, and technicians involved in our study for their participation and technical support. We would like to thank Editage (www.editage.com) for English language editing.

11. Murina F, Graziottin A, Vicariotto F, De Seta F. Can Lactobacillus fermentum LF10 and Lactobacillus acidophilus LA02 in a slow-release vaginal product be useful for prevention of recurrent vulvovaginal candidiasis?: A clinical study. J Clin Gastroenterol. (2014) 48(Suppl 1):S102-5. doi: 10.1097/MCG.0000000000000225

12. Hemmerling A, Harrison W, Schroeder A, Park J, Korn A, Shiboski S, et al. Phase 1 dose-ranging safety trial of Lactobacillus crispatus CTV-05 for the prevention of bacterial vaginosis. Sex Transm Dis. (2009) 36:564-9. doi: 10.1097/OLQ.0b013e3181a74924

13. Stapleton AE, Au-Yeung M, Hooton TM, Fredricks DN, Roberts PL, Czaja CA, et al. Randomized, placebo-controlled phase 2 trial of a Lactobacillus crispatus probiotic given intravaginally for prevention of recurrent urinary tract infection. Clin Infect Dis. (2011) 52:1212-7. doi: 10.1093/cid/cir183

14. Pirotta M, Gunn J, Chondros P, Grover S, O’Malley P, Hurley S, et al. Effect of Lactobacillus in preventing post-antibiotic vulvovaginal candidiasis: a randomised controlled trial. BMJ. (2004) 329:548. doi: 10.1136/bmj.38210.494977.DE

15. Martinez RC, Franceschini SA, Patta MC, Quintana SM, Candido RC, Ferreira JC, et al. Improved treatment of vulvovaginal candidiasis with fluconazole plus probiotic Lactobacillus rhamnosus GR-1 and Lactobacillus reuteri RC-14. Lett Appl Microbiol. (2009) 48:269-74. doi: 10.1111/j.1472-765X.2008.02477.x

16. Laue C, Papazova E, Liesegang A, Pannenbeckers A, Arendarski P, Linnerth B, et al. Effect of a yoghurt drink containing Lactobacillus strains on bacterial vaginosis in women - a double-blind, randomised, controlled clinical pilot trial. Benef Microbes. (2018) 9:35-50. doi: 10.3920/BM2017.0018

17. Hemmerling A, Harrison W, Schroeder A, Park J, Korn A, Shiboski S, et al. Phase 2a study assessing colonization efficiency, safety, and acceptability of Lactobacillus crispatus CTV-05 in women with bacterial vaginosis. Sex Transm Dis. (2010) 37:745-50. doi: 10.1097/OLQ.0b013e3181e50026

18. Komesu YM, Dinwiddie DL, Richter HE, Lukacz ES, Sung VW, Siddiqui NY, et al. Defining the relationship between vaginal and urinary microbiomes. Am J Obstet Gynecol. (2020) 222:154.e1-e10. doi: 10.1016/j.ajog.2019.08.011

19. Witkin SS, Linhares IM, Giraldo P. Bacterial flora of the female genital tract: function and immune regulation. Best Pract Res Clin Obstet Gynaecol. (2007) 21:347-54. doi: 10.1016/j.bpobgyn.2006.12.004

20. Kim DE, Kim JK, Han SK, Jang SE, Han MJ, Kim DH. Lactobacillus plantarum NK3 and Bifidobacterium longum NK49 alleviate bacterial vaginosis and osteoporosis in mice by suppressing NF- $\kappa \mathrm{B}$-linked TNF- $\alpha$ expression. J Med Food. (2019) 22:1022-31. doi: 10.1089/jmf.2019.4419

21. Chetwin E, Manhanzva MT, Abrahams AG, Froissart R, Gamieldien H, Jaspan H, et al. Antimicrobial and inflammatory properties of South African 
clinical Lactobacillus isolates and vaginal probiotics. Sci Rep. (2019) 9:1917. doi: 10.1038/s41598-018-38253-4

22. Serrano MG, Parikh HI, Brooks JP, Edwards DJ, Arodz TJ, Edupuganti L, et al. Racioethnic diversity in the dynamics of the vaginal microbiome during pregnancy. Nat Med. (2019) 25:1001-11. doi: 10.1038/s41591-019-0465-8

23. Fettweis JM, Serrano MG, Brooks JP, Edwards DJ, Girerd PH, Parikh HI, et al. The vaginal microbiome and preterm birth. Nat Med. (2019) 25:1012-21. doi: 10.1038/s41591-019-0450-2

24. Mousavi E, Makvandi M, Teimoori A, Ataei A, Ghafari S, Najafian $\mathrm{M}$, et al. In vitro adherence of Lactobacillus strains isolated from the vaginas of healthy Iranian women. J Chin Med Assoc. (2016) 79:665-71. doi: 10.1016/j.jcma.2016.04.007

25. Yang S, Reid G, Challis JRG, Gloor GB, Asztalos E, Money D, et al. Effect of oral probiotic Lactobacillus rhamnosus GR-1 and Lactobacillus reuteri RC14 on the vaginal microbiota, cytokines and chemokines in pregnant women. Nutrients. (2020) 12:368. doi: 10.3390/nu12020368

26. Iseppi R, Messi P, Camellini S, Sabia C. Bacteriocin activity of Lactobacillus brevis and Lactobacillus paracasei ssp. paracasei. J Med Microbiol. (2019) 68:1359-66. doi: 10.1099/jmm.0.001045

27. Fuochi V, Coniglio MA, Laghi L, Rescifina A, Caruso M, Stivala A, et al. Metabolic characterization of supernatants produced by Lactobacillus spp. with in vitro anti-legionella activity. Front Microbiol. (2019) 10:1403. doi: $10.3389 /$ fmicb. 2019.01403

28. Hutt P, Lapp E, Stsepetova J, Smidt I, Taelma H, Borovkova N, et al. Characterisation of probiotic properties in human vaginal lactobacilli strains. Microb Ecol Health Dis. (2016) 27:30484. doi: 10.3402/mehd.v27.30484

29. Pino A, Bartolo E, Caggia C, Cianci A, Randazzo CL. Detection of vaginal lactobacilli as probiotic candidates. Sci Rep. (2019) 9:3355. doi: 10.1038/s41598-019-40304-3

30. Parolin C, Marangoni A, Laghi L, Foschi C, Nahui Palomino RA, Calonghi $\mathrm{N}$, et al. Isolation of vaginal lactobacilli and characterization of anti-candida activity. PLoS One. (2015) 10:e0131220. doi: 10.1371/journal.pone.0131220

31. Niu XX, Li T, Zhang X, Wang SX, Liu ZH. Lactobacillus crispatus modulates vaginal epithelial cell innate response to Candida albicans. Chin Med J. (2017) 130:273-9. doi: 10.4103/0366-6999.198927

32. Franklin AL, Todd T, Gurman G, Black D, Mankinen-Irvin PM, Irvin RT. Adherence of Pseudomonas aeruginosa to cilia of human tracheal epithelial cells. Infect Immun. (1987) 55:1523-5. doi: 10.1128/IAI.55.6.1523-1525.1987

33. Melgaco ACC, Blohem Pessoa WF, Freire HP, Evangelista de Almeida M, Santos Barbosa M, Passos Rezende R, et al. Potential of maintaining a healthy vaginal environment by two Lactobacillus strains isolated from cocoa fermentation. Biomed Res Int. (2018) 2018:7571954. doi: $10.1155 / 2018 / 7571954$

34. Ortiz L, Ruiz F, Pascual L, Barberis L. Effect of two probiotic strains of Lactobacillus on in vitro adherence of Listeria monocytogenes, Streptococcus agalactiae, and Staphylococcus aureus to vaginal epithelial cells. Curr Microbiol. (2014) 68:679-84. doi: 10.1007/s00284-014-0524-9

35. Mastromarino P, Brigidi P, Macchia S, Maggi L, Pirovano F, Trinchieri $\mathrm{V}$, et al. Characterization and selection of vaginal Lactobacillus strains for the preparation of vaginal tablets. J Appl Microbiol. (2002) 93:884-93. doi: 10.1046/j.1365-2672.2002.01759.x

36. Zeng Z, Zuo F, Marcotte H. Putative adhesion factors in vaginal Lactobacillus gasseri DSM 14869: functional characterization. Appl Environ Microbiol. (2019) 85:e00800-19. doi: 10.1128/AEM.00 800-19

37. Atassi F, Pho Viet Ahn DL, Lievin-Le Moal V. Diverse expression of antimicrobial activities against bacterial vaginosis and urinary tract infection pathogens by cervicovaginal microbiota strains of Lactobacillus gasseri and Lactobacillus crispatus. Front Microbiol. (2019) 10:2900 doi: $10.3389 /$ fmicb.2019.02900

38. Blango MG, Mulvey MA. Persistence of uropathogenic Escherichia coli in the face of multiple antibiotics. Antimicrob Agents Chemother. (2010) 54:1855-63. doi: 10.1128/AAC.00014-10

39. Rosca AS, Castro J, Sousa LGV, Cerca N. Gardnerella and vaginal health: the truth is out there. FEMS Microbiol Rev. (2020) 44:73-105. doi: 10.1093/femsre/fuz027

40. Verstraelen $\mathrm{H}$, Swidsinski A. The biofilm in bacterial vaginosis: implications for epidemiology, diagnosis and treatment: 2018 update. Curr Opin Infect Dis. (2019) 32:38-42. doi: 10.1097/QCO.0000000000000516

41. Machado D, Castro J, Palmeira-de-Oliveira A, Martinez-de-Oliveira J, Cerca $\mathrm{N}$. Bacterial vaginosis biofilms: challenges to current therapies and emerging solutions. Front Microbiol. (2016) 6:1528. doi: 10.3389/fmicb.2015.01528

42. Lee IC, Caggianiello G, van S, II, Taverne N, Meijerink M, et al. Strain-specific features of extracellular polysaccharides and their impact on Lactobacillus plantarum-host interactions. Appl Environ Microbiol. (2016) 82:3959-70. doi: 10.1128/AEM.00306-16

43. Lebeer S, Claes I, Tytgat HL, Verhoeven TL, Marien E, von Ossowski I, et al. Functional analysis of Lactobacillus rhamnosus GG pili in relation to adhesion and immunomodulatory interactions with intestinal epithelial cells. Appl Environ Microbiol. (2012) 78:185-93. doi: 10.1128/AEM.06192-11

44. Polak-Berecka M, Wasko A, Paduch R, Skrzypek T, Sroka-Bartnicka A. The effect of cell surface components on adhesion ability of Lactobacillus rhamnosus. Antonie van Leeuwenhoek. (2014) 106:751-62. doi: 10.1007/s10482-014-0245-x

45. Abedi D, Feizizadeh S, Akbari V, Jafarian-Dehkordi A. In vitro anti-bacterial and anti-adherence effects of Lactobacillus delbrueckii subsp bulgaricus on Escherichia coli. Res Pharm Sci. (2013) 8:260-8.

46. Lievin V, Peiffer I, Hudault S, Rochat F, Brassart D, Neeser JR, et al. Bifidobacterium strains from resident infant human gastrointestinal microflora exert antimicrobial activity. Gut. (2000) 47:646-52. doi: 10.1136/gut.47.5.646

47. Lee YK, Lim CY, Teng WL, Ouwehand AC, Tuomola EM, Salminen S. Quantitative approach in the study of adhesion of lactic acid bacteria to intestinal cells and their competition with enterobacteria. Appl Environ Microbiol. (2000) 66:3692-7. doi: 10.1128/AEM.66.9.3692-3697. 2000

48. Castro J, Henriques A, Machado A, Henriques M, Jefferson KK, Cerca N. Reciprocal interference between Lactobacillus spp. and Gardnerella vaginalis on initial adherence to epithelial cells. Int J Med Sci. (2013) 10:1193-8. doi: $10.7150 /$ ijms. 6304

49. Wong SS, Quan Toh Z, Dunne EM, Mulholland EK, Tang ML, RobinsBrowne RM, et al. Inhibition of Streptococcus pneumoniae adherence to human epithelial cells in vitro by the probiotic Lactobacillus rhamnosus GG. BMC Res Notes. (2013) 6:135. doi: 10.1186/1756-0500-6-135

Conflict of Interest: The authors declare that the research was conducted in the absence of any commercial or financial relationships that could be construed as a potential conflict of interest.

Copyright $\odot 2020 \mathrm{He}$, Niu, Wang, Na, Xiao and Yang. This is an open-access article distributed under the terms of the Creative Commons Attribution License (CC BY). The use, distribution or reproduction in other forums is permitted, provided the original author(s) and the copyright owner(s) are credited and that the original publication in this journal is cited, in accordance with accepted academic practice. No use, distribution or reproduction is permitted which does not comply with these terms. 